\title{
Study on Gear Plunge Shaving Cutter Generated by Grinding Worm
}

\author{
Ruei-Hung Hsu ${ }^{\mathrm{a},{ }^{*},}$, Shih-Sheng Chen ${ }^{\mathrm{b}}$ \\ aBachelor's Program of Precision Systems Design, Feng Chia University, 100 Wenhwa Rd., Taichung 40724, Taiwan \\ ${ }^{b}$ Department of Mechanical Engineering, National Chung-Hsing University, 250 Kuo-Kuang Rd., Taichung 40227, Taiwan \\ *Corresponding Author: rhhsu@fcuoa.fcu.edu.tw
}

\begin{abstract}
The gear shaving is usually used for gear finishing process before heat treatment. Gears processed by shaving can adjust the lead profile of the gears and improve the gear surface roughness after gear hobbing process. Until now, it has been used to produce gears used in the automotive industry. The gear plunge-shaving method is the fastest production method in the gear shaving processes, which reduces the number of axes of motion that must be controlled by the machine tool. However, the tooth profile of the plunge shaving cutter is a hyperboloid with hollow tooth form, and the plunge-shaving cutter is more difficult to manufacture than other conventional shaving cutter. The traditional way to manufacture the plunge-shaving cutter is to use the cone grinding wheel to generate the profile of the cutter, and under such a processing process, the production speed is relatively slow. In this subject, the idea is to use a grinding worm and control the center distance between the worm and the shaving cutter blank during the machining process to complete the plunge-shaving cutter making. Compared to using a cone grinding wheel, we will use a standard grinding worm to help speed up the cutter making process. In the article, a useful mathematical model for the gear plunge shaving cutter generated by a grinding worm is established. And also a numerical example calculation is provided to verify that the tool tooth surface topography error of this machining method is small and can be achieved.
\end{abstract}

Keywords: gear shaving, plunge shaving cutter, grinding worm.

\section{Introduction}

The gear shaving process is used for the finishing process after gear hobbing or shaping. Gear shaving is widely used in mass production gears. The gear shaving cutter is meshed with the work gear in crossed axes. In gear shaving processes, the number of machine tool axes required for the gear plunge-shaving method is minimal, and therefore it is easier to maintain accuracy when producing gears. However, the gear plunge-shaving cutter has a complex tooth profile that is hyperboloid with hollow tooth form, and it is more difficult to manufacture than the other traditional shaving cutters. Also there is a problem that the traditional manufacturing plunge-shaving cutter uses cone grinding wheel finishing tooth one by one, and processing efficiency is not high in this way. For this reason, this paper proposes to use the characteristics of continuous machining of the grinding worm and use a method of changing the center distance between it and the shaving cutter blank to complete the faster manufacturing of gear plunge-shaving cutter.

Basic mesh conditions for the crossed helical gear set and the mathematical mode of the helical gear has been derived in the textbook [1]. Fong and Hsu [2] develop a mathematical model of plunge shaving cutter ground by a cone grinding wheel. Hsu and Fong [3] proposed a mathematical model for the cutting edge of a plunge shaving cutter serration that takes into account the necessary hollow tooth form. Hsu and Fong [4] proposed a mathematical model for the cutting edge of a plunge shaving cutter serration that takes into account the necessary hollow tooth form. Hsu and Fong [5] proposed a mathematical model for a mathematical model that summarizes these instantaneous cutting marks and estimates the final plunge shaved tooth surface of the work gear. Finally, Hsu and Fong [6] proposed a mathematical model for calculating the auxiliary crowning.

Varying the center distance between the grinding worm and the shaving cutter without crossed angle compensation, this center distance variation produces a flank twist on the shaving cutter. The twist tooth form is similar to the hollow tooth form; hence we use the method of changing the center distance between the grinding worm and the shaving cutter to manufacture a plunge-shaving cutter. 


\section{Mathematical Model of the Theoretical Plunge Shaving Cutter}

The theory plunge shaving cutter can be generated by a helical gear on the plunge gear shaving machine. The coordinate systems for plunge gear shaving machine can be simplified as shown in Fig. 1. The coordinate system $S_{f}$ is rigidly connected to the frame of the shaving machine. The coordinate systems $S_{1}$ and $S_{2}$ are rigidly connected to the shaving cutter and the gear. The parameters $\phi_{1}$ and $\phi_{2}$ are the rotating angle of the shaving cutter and the gear, respectively. The center distance between the shaving cutter and the gear is $\mathrm{E}_{o}$, and the crossed angle between the cutter and the gear is $\gamma_{o}$.

The mathematical model of helical gear has been derived by textbook [1]. Assume that the position vector $\mathbf{r}_{2}\left[x_{2}\left(\mathrm{u}_{2}, \mathrm{v}_{2}\right), \mathrm{y}_{2}\left(\mathrm{u}_{2}, \mathrm{v}_{2}\right), \mathrm{z}_{2}\left(\mathrm{u}_{2}, \mathrm{v}_{2}\right), 1\right]^{T}$ and the unit normal vector $\mathbf{n}_{2}\left[x_{2}\left(\mathrm{u}_{2}, \mathrm{v}_{2}\right), \mathrm{y}_{2}\left(\mathrm{u}_{2}, \mathrm{v}_{2}\right), \mathrm{z}_{2}\left(\mathrm{u}_{2}, \mathrm{v}_{2}\right)\right]^{T}$ of the helical gear are given and represented in coordinate system $S_{2}$. The locus of the gear represented in coordinate system $S_{1}$ is shown in Eq. (1).

$\mathbf{r}_{1}\left(u_{2}, v_{2}, \phi_{1}\right)=\mathbf{M}_{12}\left(\phi_{1}\right) \cdot \mathbf{r}_{2}\left(u_{2}, v_{2}\right)$

where

$\mathbf{M}_{12}=\mathbf{M}_{1 p} \cdot \mathbf{M}_{p 2}$

$\mathbf{M}_{1 p}=\left[\begin{array}{cccc}-\cos \phi_{1} & \sin \phi_{1} & 0 & 0 \\ -\cos \gamma \sin \phi_{1} & -\cos \gamma \cos \phi_{1} & \sin \gamma & 0 \\ \sin \gamma \sin \phi_{1} & \cos \phi_{1} \sin \gamma & \cos \gamma & 0 \\ 0 & 0 & 0 & 1\end{array}\right]$

$\mathbf{M}_{p 2}=\left[\begin{array}{cccc}\cos \phi_{2} & -\sin \phi_{2} & 0 & \mathrm{E}_{o} \cos \phi_{2} \\ \sin \phi_{2} & \cos \phi_{2} & 0 & \mathrm{E}_{o} \sin \phi_{2} \\ 0 & 0 & 1 & 0 \\ 0 & 0 & 0 & 1\end{array}\right]$ (5):

The locus of the gear $\mathbf{r}_{1}$ is simplified as shown in Eq.

$\mathbf{r}_{1}=\left[x_{1}\left(u_{2}, v_{2}, \phi_{1}\right), y_{1}\left(u_{2}, v_{2}, \phi_{1}\right), z_{1}\left(u_{2}, v_{2}, \phi_{1}\right), 1\right]^{T}$

The equation of meshing between the gear and the shaving cutter is shown in Eq. (6):

$f_{1}\left(\mathrm{u}_{2}, \mathrm{v}_{2}, \phi_{1}\right)=\mathbf{n}_{1} \cdot \frac{\partial}{\partial \phi_{1}}\left[\mathrm{x}_{1}\left(\mathrm{u}_{2}, \mathrm{v}_{2}, \phi_{1}\right), y_{1}\left(\mathrm{u}_{2}, \mathrm{v}_{2}, \phi_{1}\right), z_{1}\left(\mathrm{u}_{2}, \mathrm{v}_{2}, \phi_{1}\right)\right]$

where

$\mathbf{n}_{1}=\mathbf{L}_{12} \mathbf{n}_{2}$

$\mathbf{L}_{12}$ is the up-submatrix of the order of the matrix $\mathbf{M}_{12}$.

Gear shaving is a free cutting process that removes small amounts of metal from the working surface of gear teeth, therefore the operating pitch helical angle will be constant. According to literature the rotating angle between the shaving cutter and the gear is as shown in following equation:

$\phi_{1}=\frac{N_{1}}{N_{2}} \phi_{2}$

Where $N_{1}$ and $N_{2}$ are teeth number of the shaving cutter and the gear. The parallel-shaving shaved gear be solved by using Eqs. (5), (6), (7) and (8) simultaneously.

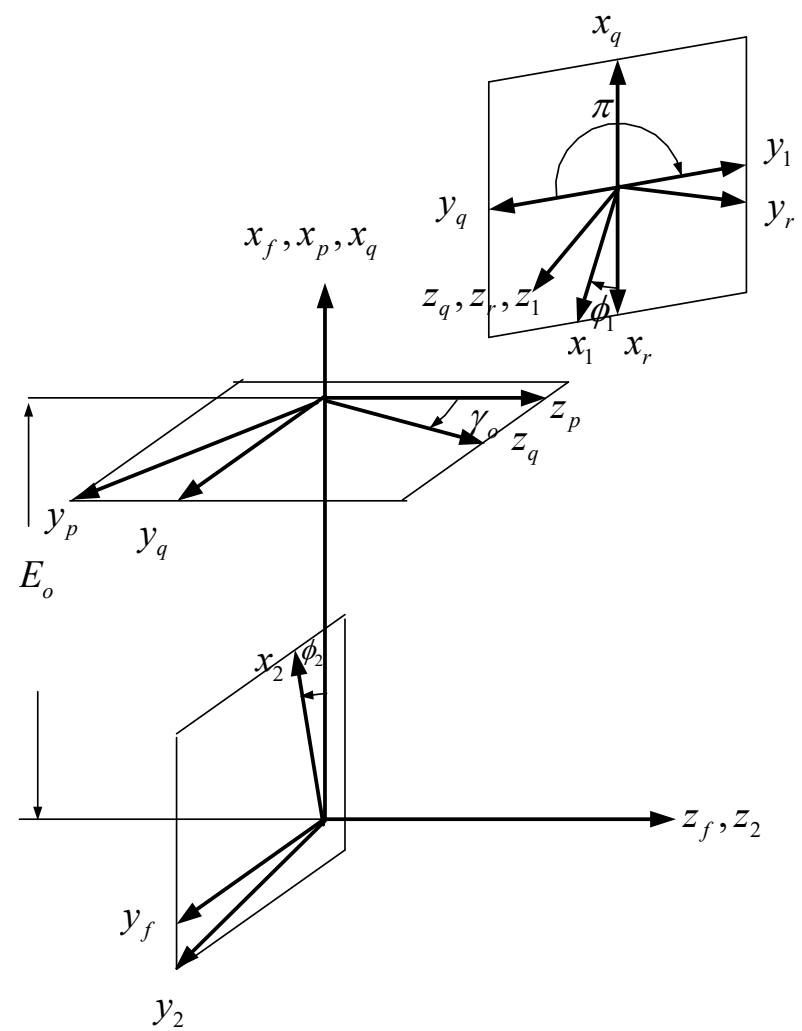

Fig. 1. Coordinate systems for plunge shaving machine.

\section{Mathematical Model of the Ground Plunge Shaving Cutter}

The ground plunge shaving cutter can be generated by a grinding worm on the grinding machine. The coordinate systems for grinding machine can be simplified as shown in Fig. 2. The coordinate system $S_{a}$ is rigidly connected to the frame of the CNC grinding machine. The coordinate systems $S_{g}$ and $S_{w}$ are rigidly connected to the grinding worm and the shaving cutter. The parameters $\phi_{g}$ and $\phi_{w}$ are the rotating angle of the grinding worm and the shaving cutter, respectively. The machine movement include the traverse movement along of the axis of the shaving cutter $z_{t}$, the 
center distance between the grinding worm and the shaving cutter $E_{g}-a z_{t}^{2}$, and the crossed angle between the grinding worm and the shaving cutter $\gamma_{g}$. The coefficient $a$ is used to change the center distance between the grinding worm and the shaving cutter.

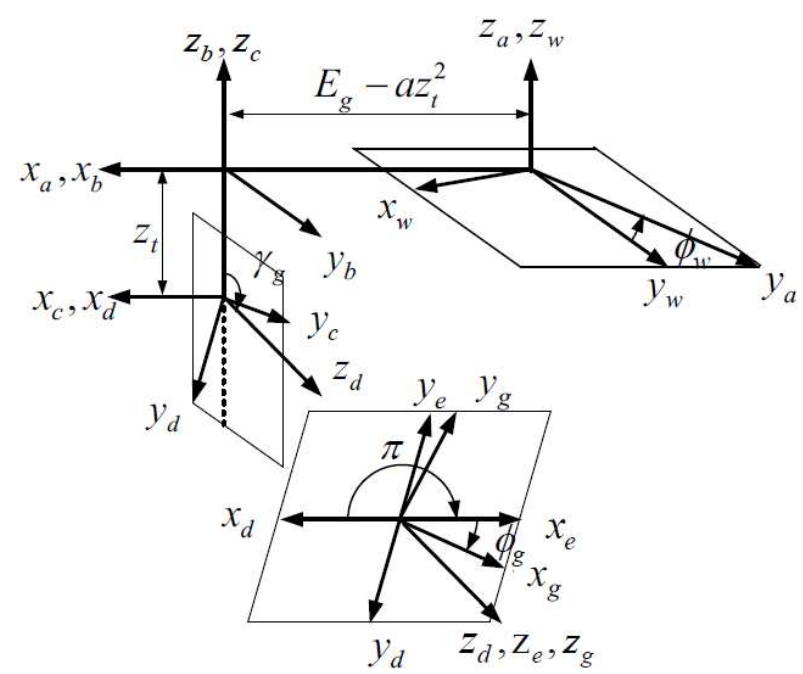

Fig. 2. Coordinate systems for $\mathrm{CNC}$ grinding machine.

The grinding worm basic form is the helical involute gear with big helix angle. Assume that the position vector $\mathbf{r}_{g}\left[x_{g}\left(\mathrm{u}_{g}, \mathrm{v}_{g}\right), \mathrm{y}_{g}\left(\mathrm{u}_{g}, \mathrm{v}_{g}\right), \mathrm{z}_{g}\left(\mathrm{u}_{g}, \mathrm{v}_{g}\right), 1\right]^{T}$ and the unit normal vector $\mathbf{n}_{g}\left[x_{g}\left(\mathrm{u}_{g}, \mathrm{v}_{g}\right), \mathrm{y}_{g}\left(\mathrm{u}_{g}, \mathrm{v}_{g}\right), \mathrm{z}_{g}\left(\mathrm{u}_{g}, \mathrm{v}_{g}\right)\right]^{T}$ of the grinding worm are given and represented in coordinate system $S_{g}$. The locus of the gear represented in coordinate system $S_{w}$ is shown in Eq. (9).

$\mathbf{r}_{w}\left(\mathrm{u}_{g}, \mathrm{v}_{g}, \phi_{g}, z_{t}\right)=\mathbf{M}_{w g}\left(\phi_{g}, z_{t}\right) \cdot \mathbf{r}_{g}\left(\mathrm{u}_{g}, \mathrm{v}_{g}\right)$

where

$\mathbf{M}_{w g}=\mathbf{M}_{w c} \cdot \mathbf{M}_{c g}$

$\mathbf{M}_{w c}=\left[\begin{array}{cccc}\cos \phi_{w} & \sin \phi_{w} & 0 & \cos \phi_{w}\left(E_{g}-a z_{a}^{2}\right) \\ -\sin \phi_{w} & \cos \phi_{w} & 0 & -\sin \phi_{w}\left(E_{g}-a z_{a}^{2}\right) \\ 0 & 0 & 1 & -z_{a}(t) \\ 0 & 0 & 0 & 1\end{array}\right]$

$\mathbf{M}_{c g}=\left[\begin{array}{cccc}-\cos \phi_{g} & -\sin \phi_{g} & 0 & 0 \\ \cos \gamma_{g} \sin \phi_{g} & -\cos \gamma_{g} \cos \phi_{g} & \sin \gamma_{g} & 0 \\ -\sin \gamma_{g} \sin \phi_{g} & \cos \phi_{g} \sin \gamma_{g} & \cos \gamma_{g} & 0 \\ 0 & 0 & 0 & 1\end{array}\right]$

The locus of the grinding worm is simplified as shown in Eq. (13):

$\mathbf{r}_{w}=\left[x_{w}\left(u_{g}, v_{g}, \phi_{g}, z_{t}\right), y_{w}\left(u_{g}, v_{g}, \phi_{g}, z_{t}\right), z_{w}\left(u_{g}, v_{g}, \phi_{g}, z_{t}\right), 1\right]^{T}$
The equation of meshing between the grinding worm and the shaving cutter is shown in Eq. (14) and Eq. (15):

$$
\begin{aligned}
& f_{2}\left(\mathrm{u}_{g}, \mathrm{v}_{g}, \phi_{g}, \mathrm{z}_{a}\right)=\mathbf{n}_{w} \cdot \frac{\partial}{\partial \phi_{g}}\left[\mathrm{x}_{w}, y_{w}, z_{w}\right] \\
& f_{3}\left(\mathrm{u}_{g}, \mathrm{v}_{g}, \phi_{g}, \mathrm{z}_{a}\right)=\mathbf{n}_{w} \cdot \frac{\partial}{\partial z_{a}}\left[\mathrm{x}_{w}, y_{w}, z_{w}\right]
\end{aligned}
$$

where

$\mathbf{n}_{w}=\mathbf{L}_{w g} \mathbf{n}_{g}$

$\mathbf{L}_{w g}$ is the up-submatrix of the order of the matrix $\mathbf{M}_{w g}$. According to literature the rotating angle between the grinding worm and the shaving cutter is as shown in following equation:

$\phi_{\mathrm{w}}=\frac{N_{g}}{N_{1}} \phi_{g} \pm \frac{\tan \beta_{p 1}}{r_{p 1}} z_{a} \quad$ (+for R.H. , - for L.H.)

Where $N_{1}$ and $N_{g}$ are teeth number of the shaving cutter and the grinding worm. The ground plunge shaving cutter solved by using Eqs. (9), (14), (15) and (16) simultaneously.

\section{Numerical examples}

This example mainly compares the theory plunge shaving cutter to the ground plunge shaving cutter. The basic data is shown in Table 1. We adopt the basic meshing condition for a crossed helical gear set derived by Litvin [1], and the basic machine setting is shown in Table 2. The Center distance movement coefficient $a$ was calculated to minimize the normal deviation on entire tooth surface between theory and ground plunge shaving cutter. The simulation topography of theory plunge shaving cutter is shown in Fig. 3. The simulation topography base is a standard helical gear, and the basic data as the same as the plunge shaving cutter. The simulation topography of ground plunge shaving cutter is shown in Fig. 4. The simulation topography of the normal deviation on entire tooth surface between theory and ground plunge shaving cutter is shown in Fig. 5, and we can find out the maximum error is $1.74 \mu \mathrm{m}$. The result shows that the method proposed in this paper using the grinding worm to make a shaving cutter is feasible. 


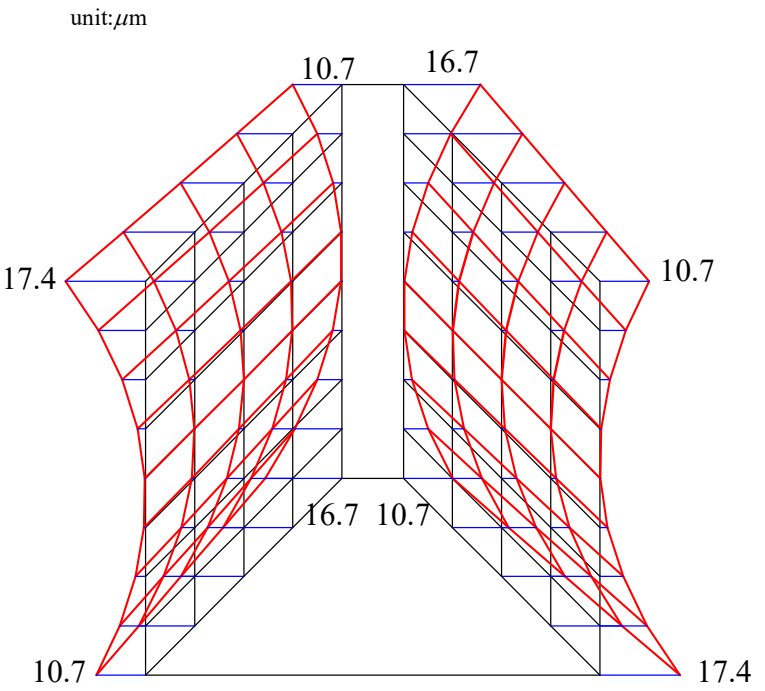

Fig. 3. Simulation topography of theory plunge shaving cutter. unit: $\mu \mathrm{m}$

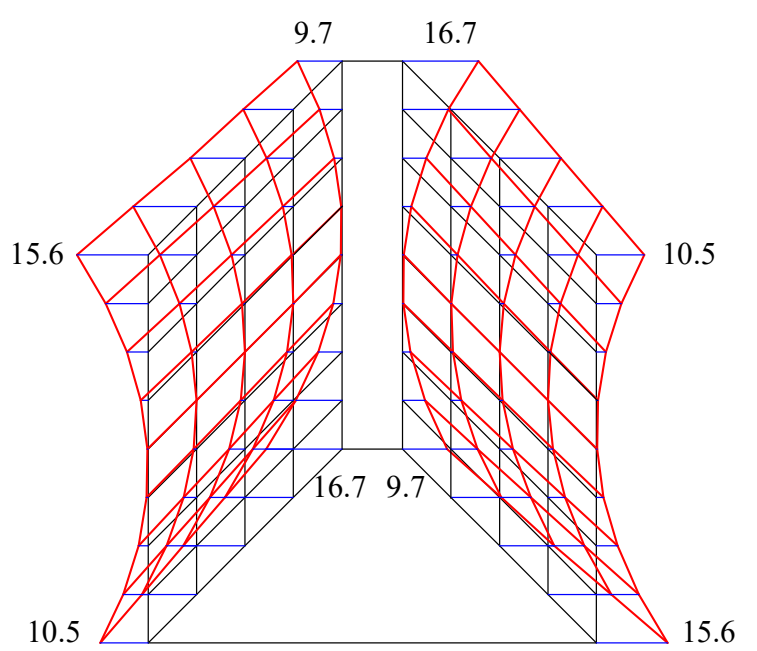

Fig 4. Simulation topography of ground plunge shaving cutter.

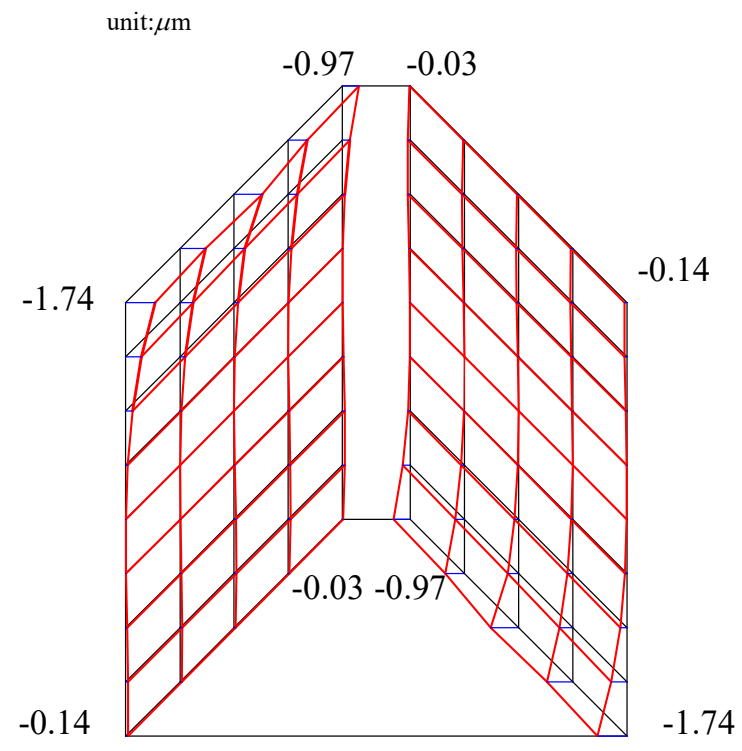

Fig 5. Simulation topography of normal deviation.
Table 1. Basic data for helical gear, plunge shaving cutter and grinding worm

\begin{tabular}{|l|l|}
\hline Helical gear & 36 \\
\hline Number of teeth $\left(N_{2}\right)$ & 2.5 \\
\hline Normal module $\left(m_{n}\right)$ & $3.927 \mathrm{~mm}$ \\
\hline Normal circular-tooth thickness $\left(s_{p n 2}\right)$ & $20^{\circ}$ \\
\hline Normal pressure angle $\left(\alpha_{p n}\right)$ & $5^{\circ}$ R.H. \\
\hline Helix angle $\left(\beta_{p 2}\right)$ & $95.344 \mathrm{~mm}$ \\
\hline Outer diameter & $86.206 \mathrm{~mm}$ \\
\hline Form diameter & $20 \mathrm{~mm}$ \\
\hline Face width & 73 \\
\hline Plunge shaving cutter & $3.927 \mathrm{~mm}$ \\
\hline Number of teeth $\left(N_{1}\right)$ & $10^{\circ}$ R.H. \\
\hline Normal circular-tooth thickness $\left(s_{p n 1}\right)$ & $181.417 \mathrm{~mm}$ \\
\hline Helix angle $\left(\beta_{p 1}\right)$ & $191.288 \mathrm{~mm}$ \\
\hline Start active diameter & 25.4 \\
\hline End active diameter & 1 \\
\hline Face width & $3.927 \mathrm{~mm}$ \\
\hline Grinding worm & $89.345^{\circ}$ R.H. \\
\hline Number of teeth $\left(N_{g}\right)$ & \\
\hline Normal circular-tooth thickness $\left(s_{p n g}\right)$ & \\
\hline Helix angle $\left(\beta_{p g}\right)$ & \\
\hline
\end{tabular}

Table 2. Plunge shaving machine and grinding machine setting.

\begin{tabular}{|l|l|}
\hline \multicolumn{2}{|l|}{ Plunge shaving machine setting } \\
\hline Operating center distance $\left(E_{o}\right)$ & $137.830 \mathrm{~mm}$ \\
\hline Operating crossed angle $\left(\gamma_{o}\right)$ & $15^{\circ}$ \\
\hline Grinding machine setting & $202.003 \mathrm{~mm}$ \\
\hline Center distance $\left(E_{g}\right)$ & 99.345 \\
\hline Crossed angle $\left(\gamma_{g}\right)$ & 0.000254 \\
\hline Center distance movement coefficient $(a)$ &
\end{tabular}

\section{Conclusions}

In this study, we use the grinding worm and a method of changing the center distance between the grinding worm and the shaving cutter blank to manufacture the plunge-shaving cutter. According to the simulation results, the maximum error of this process is about $2 \mu \mathrm{m}$ or less. In this method, it can replace the traditional use of cone grinding wheel to process plunge-shaving cutter and make the cutter in a more efficient way.

\section{Acknowledgment}

The authors are grateful to the R.O.C.'s Ministry of Science and Technology for its financial support. Part of this work was performed under Contract No. MOST 108-2221E-035-059-. 


\section{References}

(1) Litvin, F. L., 1994, Gear Geometry and Applied Theory, PTR Prentice Hall, Englewood Cliffs, NJ, pp. 412-468.

(2) Ruei-Hung Hsu, and Zhang-Hua Fong, 2005, "Topographic Error Analysis of Gear Plunge-Shaving Cutter Finished by Cone Grinding Wheel," Journal of the Chinese Institute of Engineers 29 (3) , pp. 481-492.

(3) Ruei-Hung Hsu, and Zhang-Hua Fong, 2006, " Theoretical and Practical Investigations Regarding the Influence of the Serration's Geometry and Position on the Tooth Surface Roughness by Shaving with Plunge Gear Cutter," Proceedings of the Institution of Mechanical Engineers, Part C, J. Mech. Eng. Sci. 220(2), pp. 223-242.

(4) Ruei-Hung Hsu, and Zhang-Hua Fong, " Serration Design Guidance for Gear Plunge Shaving Cutter." ASME Journal of Manufacturing Science and Engineering, 133(2):021004 A April 2011.

(5) Ruei-Hung Hsu, and Zhang-Hua Fong, 2010," Even Contact Design of the Plunge shaving cutter." Mechanism and Machine Theory 45,pp.1185-1200.

(6) Ruei-Hung Hsu, and Zhang-Hua Fong, 2010,"An Auxiliary Crowning Analysis of Parallel Gear Shaving." Mechanism and Machine Theory 45 ,pp. 1298-1313 